\title{
Estudos sobre a teoria histórico-cultural e suas implicações educacionais ${ }^{\star}$
}

No presente texto são esboçados os fundamentos teóricos de um programa de pesquisa intitulado "Estudos sobre a teoria histórico-cultural e suas implicações educacionais". Privilegia-se o eixo interpretativo ancorado na antropologia filosófica de Martin Buber por haver convergência de ideias entre ele e Vigotski, principalmente, no exame de questões do campo da educação. Para ambos estudiosos, a vida de relações é a fonte de humanização do homem; a educação é essencialmente diálogo e sua missão é nutrir possibilidades relacionais. Os estudos e pesquisas realizados no interior do referido programa visam ao exame crítico è ìterpretação da teoria histórico-cultural, buscando-se compreender as suas principais formulações no momento inaugural, na União Soviética, bem como seus desdobramentos, na atualidade, em campos da educação ligados às artes, às ciências e às humanidades. São apresentados, ao final, resumos de estudos e pesquisas realizados no âmbito do programa, com o intuito de ilustrar o enfoque adotado.

Palavras-chave: teoria histórico-cultural; psicologia; educação.

\section{Studies on the Cultural-Historical Theory and its educational implications}

\begin{abstract}
In this paper are outlined the theoretical foundations of a research program entitled "Studies on cultural-historical theory and its implications for education". The interpretative emphasis is anchored on the philosophical anthropology of Martin Buber, since there is convergence of ideas between him and Vygotsky, especially in the examination of issues in the field of education. For both, man's relationships to each other is the source of humanization of man; education is essentially dialogue and its mission is to promote relational possibilities. Studies and surveys conducted within the program are directed toward the critical examination and interpretation of the cultural-historical theory. These studies also seek understand the main formulations of the theory in its inaugural moment in the Soviet Union and its consequences for education in arts, sciences and the humanities. A few abstracts of studies and researches conducted within the scope of the program are presented.
\end{abstract}

Keywords: Cultural-Historical Theory; psychology; education.

O presente programa de pesquisa congrega projetos que visam ao exame e interpretação da teoria histórico-cultural, privilegiando campos da educação nas artes, nas ciências e nas humanidades. Para isso, buscam-se fundamentos na antropologia filosófica de Martin Buber, uma vez que esse pensador, assim como Vigotski, afirma ser a vida de relações a fonte de humanização do homem. Essa convergência entre os dois pensadores é marcante, principalmente quando eles tratam de questões ligadas à educação, conforme ilustra-se a seguir.

Essencialmente, educação é diálogo. Esse é um ponto de vista que une os dois grandes pensadores.

Buber nasceu em Viena, no dia 8 de fevereiro de 1878. Viveu um período de sua infância na Galícia, uma província sul-oriental polonesa. Era judeu e teve sua formação na mística hassídica (BARTHOLO, 2001). Sua formação no judaísmo hassídico iniciou-se na infância, na convivência com seu avô, mas foi após 1904, ao conhecer a vida e obra de Baal-Shem-Tov que decidiu abandonar o sionismo e dedicar-se exclusivamente ao estudo do hassidismo. Para Murphy (1988), esse foi um evento decisivo na vida de Buber que, daí em diante, devotou-se

\footnotetext{
^Grupo de Pesquisa "A relação entre práticas sociais instituídas e desenvolvimento cultural", coordenado por Elizabeth Tunes.

$\star \star$ Endereço para correspondência: Universidade de Brasília, Faculdade de Educação. Campus Asa Norte. ASA NORTE. CEP: 70000-000 - Brasilia, DF Brasil.E-mail: bethtunes@gmail.com
}

com intensidade ao estudo das histórias e parábolas dos mestres hassídicos e definiu um propósito e uma direção que jamais abandonaria.

Conforme Buber (1977) afirma em sua obra mais importante - Eu e Tu -, o mundo é dual para o homem e essa dualidade expressa-se nas duas palavras-fundantes $\mathrm{Eu}$-Tu e Eu-Isso. O par Eu-Tu profere-se no encontro de parceiros em reciprocidade e o Eu-Isso, quando da objetivação ou da requisição utilitária. As palavras-fundantes Eu-Tu são o suporte da vida dialógica; nesta, o eu é uma pessoa. No par Eu-Isso, o eu é um sujeito que se defronta com um objeto. No encontro dialógico, o Eu e o Tu estão presentes face a face, em reciprocidade e simultaneidade. Na relação Eu-Isso, a presença do Isso não se dá na alteridade. Somente na relação $\mathrm{Eu}-\mathrm{Tu}$, o eu presentifica-se como pessoa e o Tu como o Outro. Ser pessoa é, desse modo, ser o suporte da alteridade. Cada uma das duas palavras-fundantes expressa possibilidades existenciais distintas e instaura realidades diferentes. Cada uma delas é uma atitude diferente, uma palavra que é ato.

A relação Eu-Isso não é um mal em si; mal pode residir na escravidão humana a essa atitude, apagando da face do homem a resposta responsável, a disponibilidade para o encontro com o outro e dissolvendo no anonimato a pessoalidade da condição humana. Para Buber, o homem precisa do mundo do Isso para viver, mas quem 
vive somente a relação Eu-Isso desumaniza-se (ver BARTHOLO, 2001). Na obra Eu-Tu, Buber empreende "uma fenomenologia da palavra e uma ontologia da relação que fundamentam uma antropologia e uma ética do inter-humano" (BARTHOLO, 2001, p. 79).

Do ponto de vista buberiano, a educação não se reduz a um conjunto de princípios ou normas gerais previamente determinadas. O lugar da educação é na relação como uma palavra-ato que instaura uma realidade relacional pautada no diálogo. Isso significa ultrapassar socioculturalmente os limites da sala de aula e do mero treinamento de habilidades técnicas. Mas se, de um lado, para Buber, educar não é se deixar reduzir à transmissão de conhecimentos rotineiros e rotinizados, por outro, tampouco considera verdadeiro que o objetivo da educação seja a pretensa liberação de forças criativas no educando. Para ele, pensar assim implica pretender fixar previamente num pacote pedagógico o que supostamente deve ser desenvolvido: um pressuposto inibidor do processo de renovação criativa. A renovação não é fixável em programações preditivas. Cada educando carrega em si, desde o nascimento, o poder do novo. São os fatores situacionais e relacionais que podem favorecer ou inibir tal efetivação. O educador participa da formação do caráter do educando como um elemento singular no fluxo das relações entre este e o mundo. A possibilidade de acesso à educação do caráter do educando é franqueada pela relação dialogal de confiança que pode vir a se estabelecer como um pacto consensual entre duas pessoas. A confiança dialogal surge com o reconhecimento da integridade do educador e de seu compromisso com a verdade (ver MURPHY, 1988; BARTHOLO; TUNES; TACCA, 2010).

Assim, a relação educador-educando é, para Buber, fundamentalmente, diálogo. Isso implica que o fundamental para o educador não é falar do ou sobre o educando, mas "com" o educando. Admitindo como dimensão primordial da educação o "nutrir possibilidades relacionais", a relação educador-educando deve, necessariamente, ser pautada pela confiança mútua, na efetivação dialogal de métodos disciplinados, críticos e reflexivos de questionamento e indagação, que Buber considera essenciais para a aprendizagem e o conhecimento autênticos (MURPHY, 1988; TUNES; TACCA; BARTHOLO JR., 2005).

Vigotski nasceu quando Buber tinha por volta de 18 anos de idade. Era também de origem judaica, embora pouco se discuta sobre a influência do judaísmo em sua obra (a esse respeito, ver BLANCK, 2003). Ele afirma a constituição social da vida psíquica em que os sistemas de signos, entre eles a fala, participam de modo importante. A apropriação individual desses sistemas, que são produções culturais do homem, requer como condição primeira a relação com o outro que tenha deles algum domínio. A possibilidade de um Eu é, pois, fundada no entre nós e a ele posterior. O individual procede do social e é nele enraizado. Do lugar da Psicologia, o homem a que Vigotski se refere "é uma pessoa social = um agregado de relações sociais encarnadas num indivíduo" (VYGOTSKY, 1989, p. 66, grifos do autor). Isso implica o princípio geral de desenvolvimento que enuncia: toda função intrapsíquica foi, antes, uma função interpsíquica. Desse princípio geral deriva-se a afirmação da anterioridade do processo de instrução em relação ao do desenvolvimento das funções psíquicas, afirmação que se consubstancia no conceito de zona de desenvolvimento iminente: o que uma pessoa consegue realizar com a ajuda de outra poderá vir a realizar por si mesma. Logo, é na situação interpsicológica que brota o significado da relação pedagógica, circunscrevendo-se as ações do educador e as do educando a um espaço relacional. Também para ele, educar é, então, "nutrir possibilidades relacionais" "“O desenvolvimento procede não em direção à socialização, mas para a individuação de funções sociais (transformação de funções sociais em funções psicológicas [...])" (VYGOTSKY, 1989, p. 61). Cabe, entretanto, esclarecer que o individual ou o pessoal não está em oposição ao social, mas apresenta-se como uma forma superior de sociabilidade.

É com a missão de nutrir possibilidades relacionais que caberia ao educador a função de organizar o ambiente social de desenvolvimento do educando. A presença deste é, contudo, imperativa. De outro modo, não se cumpriria a missão: o educador se conduziria, solitariamente, como um espectro. Assim, no ato pedagógico genuíno, requer-se do educador vulnerabilidade à alteridade do educando. Responder a este significa indicar-lhe as condições que possibilitam o curso de sua ação. É esse o sentido do termo ajudar expresso no conceito de zona de desenvolvimento iminente: sustentar, manter as possibilidades de ação daquele a quem se oferece ajuda. $\mathrm{O}$ protagonismo é do educando; é ele quem confere sentido ao seu processo de aprender, restringindo, ativamente, as possibilidades de ação do educador que, por seu turno, planeja sistematicamente sua ajuda, selecionando, filtrando as condições de possibilidade para manter o curso de ação do educando. Desde essa perspectiva, ensinar e aprender traduzem-se num encontro que revela e compromete. "Se, do ponto de vista científico, negamos que o professor tenha a capacidade de exercer uma influência educativa direta, que tenha a capacidade mística de 'modelar a alma alheia', é precisamente porque reconhecemos que sua importância é incomensuravelmente" (VIGOTSKI, 2003, p. 76).Há, em Vigotski, indicações da posição buberiana que afirma o caráter dialógico do ato pedagógico genuíno (ver BARTHOLO, JR., TUNES; TACCA, 2010; TUNES; BARTHOLO JR., 2004).

Tendo por base a interpretação antropológico-filosófica de conceitos e ideias de Vigotski, foram realizados vários trabalhos, entre os quais mencionamos os que se seguem.

\section{PEDERIVA, Patrícia Lima Martins. A atividade musical e a consciência da particularidade. Tese de Doutorado em Educação, Universidade de Brasília, 2009.}

Esta pesquisa buscou analisar a musicalidade em perspectiva histórico-cultural, o que significou compreender sua gênese, estrutura e função em momentos históricos diferenciados, a saber, na história natural, na história cultural, bem como em momentos de ruptura que implicam transformações nos modos de experienciar e vivenciar a musicalidade, seja em sua forma natural de expressão, 
seja na atividade musical propiciada pela música. O instrumento metodológico utilizado foi a análise genético-psicológica de Vigotski, que possui por base a filosofia de Spinoza e o materialismo dialético marxista. Procedendo dessa forma, foi possível compreender que a musicalidade, em sua base biológica, atrelada à fala, é um dom natural de caráter universal. Na cultura, distanciando-se da fala, ela se transforma, trilhando aí novos caminhos, uma nova síntese, assumindo novas dimensões psicológicas e novos significados perante a cultura. Em relação à obra de arte, na experiência musical, criam-se condições de possibilidade para o surgimento de um novo tipo de consciência na atividade psicológica do homem, a consciência da particularidade, que auxilia na organização e no controle das próprias emoções. No desenvolvimento histórico da atividade musical, inicia-se a institucionalização escolarizada da musicalidade, processo este ancorado em valores ideológicos e mercantilistas que limitam a expressão musical, domesticando e solapando as possibilidades musicais expressivas e criativas do homem. Crê-se que tais condições poderiam ser transformadas mediante a vivificação de condições ontológicas que também são emancipadoras, a igualdade, a liberdade, a vontade, a ética, a imaginação e a criação, experienciadas em meio a relações autênticas e convivenciais.

2. PRESTES, Zoia Ribeiro. Quando não é quase a mesma coisa - Análise de traduções de Lev Semionovitch Vigotski no Brasil. Repercussões no campo educacional. Tese de Doutorado em Educação, Universidade de Brasília, 2010.

Neste trabalho, examina-se a atividade de tradução, compreendendo-a como um processo de criação em que o tradutor é um servidor da verdade do autor e suporte da alteridade deste. Não se trata, pois, de fidelidade ao texto, mas de lealdade ao homem que se faz presente no texto. As palavras do autor iluminam o leitor e devem continuar a fazê-lo quando vertidas em outra língua. De outro modo, se adulteradas, dois atos de violência são cometidos simultaneamente: contra o autor e contra o leitor, pois as palavras do autor formam um campo enevoado que tornam turva a visão do leitor. Para realizar o trabalho, tomaram-se traduções de obras do pensador soviético Lev Semionovitch Vigotski como emblemáticas e, com base na análise de traduções feitas no Brasil, procurou-se demonstrar como certos equívocos e descuidos na tradução constituem adulterações de conceitos fundamentais de sua teoria e distorcem seriamente suas ideias. Para a elaboração da tese, procedeu-se a um amplo levantamento bibliográfico, assim como a um trabalho de cotejamento textual de edições brasileiras e estrangeiras. Foi necessário também o aprofundamento de conceitos apresentados por Vigotski, o que foi feito por meio de pesquisas em fontes russas sobre a trajetória de publicações de alguns de seus textos, de entrevistas com seus familiares e com alguns estudiosos russos da teoria histórico-cultural. Discutiram-se as opções de alguns tradutores de textos de Vigotski e analisou-se a trajetória de algumas de suas obras na União Soviética, na Rússia e no Brasil. Com base no exame detalhado de alguns conceitos basilares de sua teoria, são apresentadas e justificadas algumas sugestões alternativas de tradução, procurando-se mostrar que algumas adulterações intencionais na tradução de obras de Vigotski escondem-se sob um véu ideológico quase imperceptível para o leitor. Finalmente, com base em fatos, documentos e depoimentos, apresentam-se algumas informações inéditas no Brasil sobre a trajetória profissional de Vigotski, destacando, entre elas, a sua relação com Aleksei Nikolaievitch Leontiev e a importância deste para a psicologia soviética, ao contribuir para a elaboração e o desdobramento da teoria histórico-cultural.

\section{RAAD, Ingrid Lilian Fuhr. Atividades cotidianas e o pensamento conceitual. Tese de Doutorado em Educação, Universidade de Brasília, 2013.}

Na sociedade contemporânea é bastante difundida a ideia de que o conhecimento científico é superior ao conhecimento que se forja nas atividades cotidianas. Para acessar o conhecimento científico, é preciso ingressar na escola, que cumpre a função de controle e tutela social do processo de ensino-aprendizagem. Os conceitos científicos são convertidos em conteúdos curriculares didatizados e relacionados aos conceitos cotidianos, para serem compreendidos; assim, eles são transformados em conceitos escolares, que apresentam um caráter híbrido. Para analisar a suposta superioridade dos conceitos científicos sobre os cotidianos, tomou-se, como referência, os estudos de Vigotski, que elaborou um trabalho sistemático sobre essa distinção. Para o exame da referida distinção, esclareceu-se o que vem a ser o cotidiano e o conhecimento científico, ou seja, a natureza das atividades cotidianas e científicas. No presente estudo, procedeu-se a uma descrição e a uma análise dos modos de organização do pensamento conceitual de duas atividades: a do artesão ourives e a do sineiro. Verificou-se que o pensamento deles contém conceitos provenientes da ciência e conceitos provenientes da própria atividade. Com todos os exames realizados, foi possível apontar indícios de que os conhecimentos são híbridos e de que há uma infinidade de modos de conhecer e operar o pensamento por conceito, seja na ciência, seja na atividade escolar ou na artesanal.

\section{BRITO, Ildamar de Farias. Desenvolvimento infantil: concepções de professores e suas implicações na manifestação do preconceito. Dissertação de Mestrado em Educação, Universidade de Brasília, 2005.}

Nesse trabalho, desenvolveu-se um estudo sobre as concepções de desenvolvimento de professores. Buscou-se investigar se tais concepções estariam implicadas na manifestação do preconceito dirigido a pessoas eleitas como deficientes e se elas possuiriam raízes em teorias científicas da psicologia. As ações do homem assentam-se em concepções que carregam modos específicos de ver as coisas e as pessoas e de se relacionar com elas. As práticas educativas de professores encontram-se ancoradas também em concepções que eles possam ter acerca do desenvolvimento infantil. Este pode ser concebido, pelo menos, a partir de duas matrizes distintas de pensamento que implicam dois eixos básicos de acordo com 
os quais o desenvolvimento pode ser caracterizado: os eixos hierarquia - uniformidade - e não hierarquia - diversidade. As matrizes de pensamento que comportam esses eixos são, respectivamente, a matriz naturalista e a histórico-cultural, que correm em dois leitos distintos da psicologia do desenvolvimento. Houve, entre as professoras que participaram do estudo, uma predominância das características encontradas na matriz naturalista do desenvolvimento. Houve também tendência a orientar a educação escolar pela lei do menor esforço, como prática tutelada - tuteladora e assistencialista - e a conceber a educação como mera aplicação da técnica. Essas tendências permitem a manifestação do preconceito no ambiente escolar em relação às pessoas instituídas como deficientes. O preconceito pode ser considerado uma importante barreira para uma inclusão escolar verdadeira. A escola contemporânea, excludente desde o princípio, tem criado as condições de possibilidade para a emergência e manifestação do preconceito. Assim, para que haja a possibilidade de práticas de educação escolar não excludentes, apontou-se para a necessidade de uma reforma radical na instituição escolar.

5. RAAD, Ingrid Lilian Fuhr. Deficiência como iatrogênese. A medicina, a família e a escola como cúmplices no processo de adoecimento. Dissertação de Mestrado em Educação, Universidade de Brasília, 2007.

$\mathrm{O}$ presente trabalho teve como objetivo analisar o modo como o rótulo da deficiência, em uma sociedade medicalizada, provoca o adoecimento do humano, ao estigmatizar a pessoa, fazendo com que ela seja vista como objeto de conhecimento científico. Examina-se a vida medicalizada orientada pelo racionalismo científico e a consequente transformação dos problemas sociais em patologias. Examina-se ainda o uso do diagnóstico pela medicina, que desenvolve o poder de categorizar, de normalizar e de normatizar a vida e que, juntamente com suas parcerias institucionais - escola e família -, atua na fabricação de deficiências. Os efeitos provocados pela medicalização geram uma doença epidêmica, a iatrogênese, que implica a perda da autonomia e do controle da própria vida. A intenção foi examinar se o fenômeno da deficiência pode ser caracterizado como um efeito iatrogênico social e estrutural do conhecimento e da prática médica. Para tanto, a reflexão foi realizada com base em um cenário da narrativa de vida de duas jovens rotuladas como deficientes mentais. $\mathrm{O}$ estudo está estruturado em três capítulos intercalados com as histórias. $\mathrm{O}$ primeiro historiza a medicina clínica e discute as bases da medicalização da sociedade, com referência à expropriação da saúde e ao desenvolvimento da iatrogenia. O segundo aborda o poder do diagnóstico, o rótulo que tece mentes deficientes. $\mathrm{O}$ terceiro analisa o conceito de deficiência na perspectiva histórico-cultural e examina o efeito do princípio do embrutecimento em relação à ratificação da homogeneização e da mesmidade. Finalmente, este estudo propôs-se a contribuir para a reflexão sobre a presença das ciências médicas e psicológicas no cotidiano, as quais criam realidades ficcionais, uma vez que não estão vinculadas às necessidades da vida pautada na ética do humano.
6. KELLY, Brenda Oliveira. A mágica da exclusão. Sujeitos invisíveis em salas especiais. Dissertação de Mestrado em Educação, Universidade de Brasília, 2012.

O presente trabalho emergiu da vivência da pequisadora com dois alunos com diagnóstico de autismo alocados em uma sala do ensino especial, de uma escola pública, do ensino regular de Brasília. Como resultado de sete meses de vivência e intervenção no contexto da escola mencionada, com os referidos alunos, buscou-se realizar um exame crítico da realidade da educação especial naquele contexto, visando a identificar, em sua própria estrutura, os mecanismos que condicionam a exclusão das crianças que as frequentam. Por meio de narrativas do cotidiano das salas especiais, mais especificamente de episódios vividos com os dois principais participantes desta pesquisa, foram realizados exames teóricos, que apontaram para a mecanicidade dos processos de ensino, para o desrespeito às necessidades individuais dos alunos com deficiência (inclusive diante de seus desenvolvimentos orgânicos, naturais) e para a falta de diálogo nas relações que se estabelecem com eles. Embora cresça o entendimento moral de que não se deve excluir pessoas com deficiência dos processos coletivos, as salas especiais constituem um mecanismo que visa a agregar, sem, no entanto, permitir a convivência verdadeira, o que acaba levando os alunos por elas atendidos a um processo gradual de invisibilização, que pode chegar ao aniquilamento social. Por fim, apresentou-se o resultado das intervenções pedagógicas em que a pesquisadora propôs a utilização do computador e em que os dois participantes da pesquisa, a despeito do que profetizavam seus diagnósticos, demonstraram ser capazes de aprender.

7. MOURA, Camila Hernandez. Estudo sobre relações sociais de pessoas com síndrome de Asperger. Dissertação de Mestrado em Psicologia, Centro Universitário de Brasília.

Em uma sociedade que anseia por resultados imediatos a fim de solucionar a maioria dos problemas, os diagnósticos são instrumentos valorizados em demasia. Entretanto, eles resolvem ou acentuam a problemática? A pessoa com síndrome de Asperger é destacada nos manuais de classificação por suas características patológicas, que destoam da normalidade instituída socialmente, enfatizando os possíveis prejuízos, falhas, dificuldades e déficits. De modo geral, abordam a deficiência em seu caráter quantitativo, colocando a criança em uma posição negativa e buscando causas em anomalias orgânicas ou na própria pessoa. Com base no DSM IV, a síndrome de Asperger apresenta uma série de características identificadas como defeituosas: dificuldades nas habilidades de comunicação, além de comportamentos, interesses e atividades restritivas. Como consequência, essas pessoas desenvolvem problemas na interação social, que interferem em suas condutas pessoais e ocupacionais. Tendo isso em vista, pode-se questionar os manuais de classificação ao afirmarem que a dificuldade de aproximação social é apontada como atributo da síndrome e como dificuldade das crianças de conviver com as demais pessoas que as cercam. A 
convivência pessoal e profissional com crianças e jovens com síndrome de Asperger despertou questionamentos a respeito do processo de interação social dessas pessoas. $\mathrm{O}$ questionamento mais importante era dirigido à forma como as outras pessoas se relacionavam com aqueles que apresentavam tal síndrome. Será que a reação do outro, talvez envolta em preconceitos, contribuiria para o déficit de interação social daqueles com síndrome de Asperger? Diversos estudos expõem a dificuldade dessas pessoas de se relacionarem com o outro, imputando-lhes uma suposta preferência pelo isolamento social. Contudo, pouco é mencionado sobre o que a sociedade faz para reafirmar essa problemática. Pergunta-se, então: a dificuldade de interação social é qualidade inerente à pessoa com síndrome de Asperger? A interação social envolve no mínimo duas pessoas, que se influenciam reciprocamente, podendo interferir nos comportamentos, pensamentos e opiniões. Então, por que, ao pensar sobre a interação social de pessoas com síndrome de Asperger, tende-se a focalizar apenas um lado da díade em vez de se observar toda a relação? Será possível que a dificuldade de socialização se refira apenas a uma das partes da relação? Qual o critério para se definir dificuldade? A partir desses questionamentos, propõe-se, no presente trabalho, examinar o outro significativo para a pessoa com síndrome de Asperger, buscando compreender como esta avalia a sua própria situação social. O estudo da defectologia, proposto por Vigotski, tem fundamental relevância, pois permite indagar sobre o sistema classificatório do diagnóstico, identificando aspectos qualitativos do problema e percebendo as crianças com síndrome de Asperger para além da deficiência. Essas crianças podem apresentar um desenvolvimento atípico, organizando-se de forma diferente e única, o que não quer dizer que sejam menos ou pior desenvolvidas. Assim, espera-se que o exame do outro significativo para a pessoa com síndrome de Asperger, bem como a compreensão de como esta avalia a sua própria situação social possa contribuir não só no que diz respeito ao diagnóstico, mas em melhores intervenções clínicas e atuações escolares para que as pessoas do ambiente social de desenvolvimento possam estar atentas às suas próprias ações diante daqueles que apresentam essa síndrome. O intuito é a compreensão das peculiaridades interativas da pessoa que apresenta Síndrome de Asperger e a consequente promoção de seu desenvolvimento, bem-estar e pertencimento a um mundo que também é dela. Para investigar esse problema, foram realizadas entrevistas com pessoas diagnosticadas com a síndrome e com seus pais. Os participantes foram selecionados pela faixa etária (entre 11 e 15 anos), pela disponibilidade de horário compatível com a da pesquisadora e pelo consentimento de seus pais.

\section{Referências}

BARTHOLO JR., R. Você e Eu: Martin Buber, presença palavra. Rio de Janeiro: Garamond, 2001.

BARTHOLO JR., R.; TUNES, E.; TACCA, M. C. V. R. Vygotsky's and Buber's pedagogical perspectives: some affinities. Educational Philosophy and Theory (Print), [S.1.], v. 42, p. 867-880, 2010.
BLANCK, G. Prefácio. In: VIGOTSKI, L. S. Psicologia pedagógica. Tradução de Claudia Schilling. Porto Alegre: Artmed, 2003.

BUBER, M. Eu e Tu. Tradução de Newton Aquiles Von Zuben. São Paulo: Cortez e Moraes, 1977.

MURPHY, D. Martin Buber's philosophy of education. Dublin: Irish Academic Press, 1988.

TUNES, E.; BARTHOLO JR., R. S. Da constituição da consciência a uma Psicologia ética: alteridade e zona de desenvolvimento proximal. In: SIMÃO, L. M.; MITJÁNS, A. (Org.). O outro no desenvolvimento humano: diálogo para a pesquisa e a prática profissional em Psicologia. São Paulo: Pioneira Learning Thomson, 2004.

TUNES, E.; TACCA, M. C. V. R.; BARTHOLO JR., R.S. O professor e o ato de ensinar. Cadernos de Pesquisa, [S.1.], v. 35, n. 126, p. 689-698, set./dez. 2005.

VYGOTSKY, L. S. Concrete Human Psychology. Soviet Psychology, [S.1.], v. 27, n. 2, p. 53-77, 1989.

VIGOTSKI, L. S. Psicologia pedagógica. Tradução de Claudia Schilling. Porto Alegre: Artmed, 2003.

Recebido em: 29 de agosto de 2013 Aceito em: 03 de setembro de 2014 